\title{
Sequential sampling protocol for monitoring pasture utiliza- tion using stubble height criteria
}

\author{
DAVID L. TURNER AND WARREN P. CLARY
}

Authors are statistician, Rocky Mountain Research Station, Forestry Sciences Laboratory, 860 North 1200 East, Logan, Ut. 84321 and supervisory range scientist, Rocky Mountain Station, Forestry Sciences Laboratory, 316 E. Myrtle Street, Boise, Ida. 83702.

\begin{abstract}
Stubble height, a measure of the amount of vegetation remaining after grazing, is thought to be a useful variable in the management of riparian areas. A number of riparian and grazing processes appear to be directly or indirectly affected by the residual stubble height. Thus, average stubble height is often used to evaluate the livestock impact a pasture has received, particularly in riparian zones. Stubble height sampling methodology has received little previous attention. A sequential sampling procedure for stubble height was investigated. The procedure provides statistically defensible answers in the shortest possible amount of time. The procedure does not require a rigid sample size and involves simple yes/no answers at each observation. A small initial sample of readings is selected and evaluated. If there is sufficient information to make a clear decision, then grazing is either continued or stopped. If the initial evidence does not clearly support either decision, then sampling proceeds. This may continue for several iterations before a decision is reached. Statistically supportable decisions can typically be made within a short time frame using this method. This method may also be applied to evaluate trampling and other yes/no responses.
\end{abstract}

Key Words: grazing management, riparian areas

Stubble height criteria are often applied as guides in the grazing management of riparian areas (USDA-FS 1993, 1994, Hall and Bryant 1995, Leonard et al. 1997, Mosley et al. 1997, Oregon State University 1998, USDA-NRCS 1999). This measure of the herbaceous vegetation remaining after grazing is most appropriately used as a short-term guide applied to attain long-term ecological objectives. Experienced observation and limited research have suggested that a number of riparian processes and characteristics can benefit, directly or indirectly, when a minimum amount of stubble height remains after grazing (Clary and Leininger 200x). Other than in mountain meadows, the use of stubble height has not been directly tested in many riparian sites and, indeed, there have been indications that other management criteria may be more effective in some situations.

When stubble height is used to make management decisions, it is important that those decisions are based upon reliable data. It is easier to sample stubble heights than some other attributes, however, accurate sampling of stubble height is not as simple as it

Appreciation is expressed to Don Oman and Seth Phalen, Sawtooth National Forest, for assistance in field testing of this procedure.

Manuscript accepted 23 Jun. 2000.
Resumen

Se piensa que la altura del restrojo, una media de la cantidad de vegetación remanente después del apacentamiento, es una variable útil en el manejo de áreas ribereñas. Un número de procesos ribereños y de apacentamiento parecen ser afectados directa o indirectamente por la altura del restrojo remanente. Así, el promedio de la altura del restrojo a menudo es utilizado para evaluar el impacto del ganado en el potrero, particularmente en zonas ribereñas. La metodología de muestreo de la altura del rastrojo ha recibido poca atención. Se investigo un procedimiento de muestreo secuencial para la altura del restrojo. El procedimiento provee respuestas estadísticamente defendibles en el mas corta cantidad de tiempo posible. El procedimiento no requiere de un tamaño de muestra rígido e involucra respuestas simples de si/no para cada observación. Una pequeña muestra inicial de lecturas es seleccionada y evaluada. Si hay suficiente información para tomar una decisión clara, entonces el apacentamiento es continuado o detenido. Si la evidencia inicial no soporta claramente cualquiera de las decisiones entonces se procede a muestrear. Esto puede continuar para varias repeticiones antes de lograr tomar una decisión. Las decisiones estadísticamente soportables típicamente pueden ser tomadas en un corto tiempo utilizando este método. Este método también puede ser aplicado para evaluar el pisoteo y otras respuestas de si/no.

may first appear. Although stubble heights can be quite uniform, as with most variables in nature, substantial variation is often present within the sampling domain. Vegetation within some locations in a pasture may be much shorter than a target height or standard while other locations may be much taller, making it difficult to decide whether the average stubble height over the entire pasture is shorter or taller than a given standard. This complicates the decision whether or not to continue grazing. Another complication in many pastures is the presence of several distinctly different strata. For example, $5 \mathrm{~cm}$ may be a reasonable stubble height in stands of bluegrass, but $15 \mathrm{~cm}$ may be more appropriate for streamside sedge communities or wet portions of the pasture. The management criteria may be to stop grazing when $50 \%$ or more of the possible plots in the drier portion of the pasture are utilized to an average stubble height of $5 \mathrm{~cm}$ or less, or if $50 \%$ or more of the possible streamside sedge plots are grazed to a stubble height of $15 \mathrm{~cm}$ or less.

Although Canfield (1942) proposed a shortcut method for estimating grazing use, his procedure lacks statistical rigor and it may not be applicable beyond the southwest area in which it was developed. Instead, perhaps the classical method for answering 
such questions is to determine utilization for a predetermined number of randomly sampled plots and use the sample information to make inferences about the entire population, which is the pasture. If the proportion of plots utilized in the random sample is "much" less than the standard, grazing is allowed to continue. If the proportion of plots utilized in the sample is "much" more than the standard, then grazing is stopped. A rigorous definition of "much more" and "much less" may be developed using statistical hypothesis tests with a discussion of sample sizes necessary to obtain specified type I and II error rates. Introductory statistical methods texts such as Ostle and Mensing (1975) or Moore and McCabe (1989) provide thorough coverage of classical statistical testing.

An alternative to classical testing methods is to take repeated small samples until enough evidence for a decision is accumulated. This process is known as sequential sampling, and is the focus of this paper. Mood et al. (1974) or Ostle and Mensing (1975) provide readable methodological background and development material.

\section{Sequential Sampling}

Sequential sampling starts by selecting a series of relatively small samples and evaluating the cumulative evidence after each sample. At each evaluation, 1 of 3 decisions is made: continue grazing if the data show "clearly" that the stubble height utilization percentage is less than the target; stop grazing if the data show "clearly" that the stubble height utilization percentage exceeds the target; or take another sample if the data are indeterminate. "Clearly" is used to indicate that enough information has accumulated to allow a definitive conclusion for a statistical test. When 40 to $50 \%$ of the population of plots have been grazed to an average stubble height lower than some target value, grazing should stop. However, the difficulty comes in trying to decide when this stage has been reached based on a relatively small sample of plots. Sequential sampling provides 1 method of resolving this difficulty.

Although actual measurements could be made at each sampling location and a running mean and standard error computed after each sample, this is more precision than required for our purposes. Instead, we classify a sampled plot as utilized or not (yes/no). The running proportion of utilized plots is then used to make inferences about the utilization level of the entire pasture.

We define a plot as utilized if the average stubble height in the plot is equivalent to or shorter than a specified target value.
For example, if a manager feels that it is time to stop grazing when the average stubble height over the pasture is $5 \mathrm{~cm}$ or less, then $5 \mathrm{~cm}$ would be the target value. An individual plot would be utilized if the average stubble height over the plot is less than $5 \mathrm{~cm}$. If the entire pasture were divided into uniform sized plots, it would be defined as fully utilized if the proportion of utilized plots (denoted $\pi$ ) exceeded some specified target value. For example, if more than $50 \%$ of all plots are utilized, then the entire pasture is defined as utilized.

Four values must be specified to define a sequential sampling procedure. First is a target value defined as the optimum or desired percent utilization. Without loss of generality, if $40 \%$ or less of a pasture is utilized, then it is generally safe to allow grazing to continue. This $40 \%$ would be the value specified in the classical null hypothesis of statistical testing using a random sample, i.e., $\mathrm{H}_{\mathrm{o}}$ : Utilization proportion $\left(\pi_{\mathrm{o}}\right) \leq 0.40$. The target utilization proportion ( 0.40 or $40 \%$ here) is in general denoted $\pi_{\mathrm{o}}$ and the null hypothesis is written in general terms as $\mathrm{H}_{\mathrm{o}}: \pi \leq \pi_{\mathrm{o}}$.

The second value is an alternative proportion. In classical hypothesis testing, this is the opposite of the null hypothesis, i.e., $\mathrm{H}_{\mathrm{a}}$ : Utilization proportion $(\pi) \geq 0.40$ or $\mathrm{H}_{\mathrm{a}}: \pi \geq 0.40$. In sequential sampling, we instead specify an upper limit. For example, if $40 \%$ is the target value, it may be reasonable to allow grazing to continue even if the sample utilization proportion reaches $50 \%$. Sequential sampling tests the null hypothesis $\mathrm{H}_{\mathrm{o}}: \pi=0.40$ against the alternative hypothesis $\mathrm{H}_{\mathrm{a}}: \pi=0.50$. Note that for all practical purposes, the null and alternate hypotheses may be written as before to include ranges of values, i.e., $\mathrm{H}_{\mathrm{o}}: \pi \leq 0.40$ and $\mathrm{H}_{\mathrm{a}}: \pi \geq 0.50$. The alternate utilization proportion $(0.50$ or $50 \%$ here) is in general denoted $\pi_{\mathrm{a}}$. The indeterminate region between 0.40 and 0.50 where neither hypothesis is supported may be viewed as a "warning" area, i.e., since utilization will increase as long as the animals are present, time on the pasture is growing short.

\section{Types of Errors}

Before testing, we must discuss the kinds of errors that can be made. Since one or a series of samples are being used to make inferences about the entire population or pasture, any decision made could be incorrect. If we reject the null hypothesis by concluding that the utilization proportion is greater than $40 \%$, a type I error would be made if the true (but unknown to us) utilization proportion over the entire pasture was in fact less than $40 \%$. The consequence of this type of error is that the animals would be moved too early. From a resource manager's point of view, this is a conservative approach which helps to insure protection of the resource. The type I error rate is denoted by $\alpha$ and values of 0.05 and 0.10 are common (Moore and McCabe 1989).

The flip side is a type II error, denoted by $\beta$, which can occur only if we fail to reject the null hypothesis when it is false, i.e., we fail to reject $\mathrm{H}_{\mathrm{o}}: \pi \leq 0.40$ when in fact the utilization proportion is really $50 \%$ or more. This is a serious kind of error with a potentially severe consequence: grazing would continue longer than it should, possibly degrading or damaging the resource.

In classical hypothesis testing, type II error rates are difficult to control because they require the true underlying utilization proportion to be known. Since this is seldom the case, type II error rates are typically computed for a range of true underlying values. However, in sequential sampling, we are technically trying to decide which of 2 values is correct, the value in the null hypothesis or the value in the alternative, and so "truth" is considerably simplified. Consequently, the type II error rate can and, in fact, must be specified in order to define the sequential sampling procedure. Type II error rates of 0.05 and 0.10 are often used (Moore and McCabe 1989).

\section{Sequential Sampling Rules}

Given the 4 values, $\pi_{\mathrm{o}}, \pi_{\mathrm{a}}, \alpha$, and $\beta$, in combination with a cumulative sample of $n$ plots, threshold values of $X_{\mathrm{c}}$ and $X_{\mathrm{s}}$ are calculated to respectively indicate when grazing is to continue or stop. Grazing will continue if the number utilized in the current sample of $n$ is less than or equal to $X_{c}$, defined as $-h_{1}+s n$. Similarly, grazing will stop if the number of utilized plots in the current sample of $n$ is less than or equal to $X_{s}$, defined as $h_{2}+s n$. If the number utilized in the sample is between $X_{c}$ and $X_{s}$, then the sample evidence is inconclusive and more observations must be taken. The constants $h_{1}, h_{2}$, and $s$ are computed as

$$
\begin{aligned}
h_{1} & =(\log ((1-\alpha) / \beta)) / k \\
h_{2} & =(\log ((1-\beta) / \alpha)) / k \\
k & =\log \left(\frac{\pi_{a}\left(1-\pi_{o}\right)}{\pi_{o}\left(1-\pi_{a}\right)}\right) \\
s & =\left(\log \left(1-\pi_{o}\right) /\left(1-\pi_{a}\right)\right) / k
\end{aligned}
$$


As a practical matter, the smallest $X_{c}$ can be (and by extension $n$ ) to make a decision to continue grazing is the integer just larger than $h_{l} / s$. Similarly, the smallest $X_{s}$ can be to make a decision to stop grazing is the integer just larger than $-h_{2} /(s-1)$. Both $X_{c}$ and $X_{s}$ should be rounded up to the next largest integer and the largest of these 2 values taken as the minimum sample size. Succeeding sample sizes are chosen for convenience and can be as small as one. However, successive sample sizes are probably better if chosen closer to the initial sample size (e.g., add additional transects rather than individual plots).

The values $X_{c}$ and $X_{s}$ give a rigorous definition of "clearly" mentioned above. If the number of utilized plots in the sample is less than or equal to $X_{c}$, then the evidence is clear that the pasture is not yet utilized to the prescribed level. When the number of utilized plots in the sample is greater than or equal to $X_{s}$, then the evidence is clear that the pasture is utilized to at least the prescribed level and grazing should stop. If the number of utilized plots in the sample is between $X_{c}$ and $X_{s}$, then the sample evidence is inconclusive and further sampling must be done.

\section{Simulation Results}

Figure 1 depicts results from 1,000 simulations at each of 5 values of the true underlying utilization proportion (labeled $\left.\pi_{\text {true }}\right)$. The minimum, maximum, and average total number of observations to make a decision for a sampling plan with type I and II errors both set to 0.05 and the target and alternative utilization proportions set to 0.40 and 0.50 , respectively, are illustrated. Note that for true utilization proportions between the target and alternative proportions, the maximum sample size can get very large. In practice, if the evidence is not "clear" or conclusive after the cumu- lative sample size exceeds 100 , it is generally safe to conclude that the underlying proportion is likely close to or between the target and alternative values and so preparations should begin to halt grazing.

\section{Example}

Using the above values, $\pi_{o}=0.40, \pi_{a}=$ $0.50, \alpha=0.05$, and $\beta=0.05, k$ and $s$ are 0.4055 and 0.4497 , respectively, making $h_{1}$ and $h_{2}$ both equal 7.26. This makes the minimum sample size for continuing and stopping grazing 17 and 14, respectively, hence the initial sample should be 17 observations.

If a transect covering the pasture is about 400 paces, a sampling fraction of $400 / 17=23.5$ may be computed, meaning that a utilization plot should be classified every $23^{\text {rd }}$ pace after a random start. For example, if 12 were the random number selected from 1 through 23, sampling would occur at the $12^{\text {th }}, 35^{\text {th }}(12+23), 58^{\text {th }}$ $(35+23)$, etc. paces along the transect.

For this sample size and these values of $\pi_{o}, \pi_{a}, \alpha$, and $\beta$, the continue grazing value $\left(X_{c}\right)$ is $-h_{1}+s n=-7.26+.4497 * 17$ $=0.3849$ which is rounded up to 1 . The stop grazing value $\left(X_{S}\right)$ for 17 observations is $h_{2}+s n=7.26+.4497 * 17=15$. Hence, if 1 or fewer of the 17 sampled plots are classified as utilized after walking the transect, grazing can continue. However, if 15 or more of the 17 sampled plots are classified as utilized, grazing should stop. Otherwise further data should be collected. For convenience, 20 plots are taken for each succeeding transect. Figure 2 shows the acceptance/rejection envelope for this plan (an initial sample of 17, succeeding samples depending on the cumulative number of utilized plots). Figure 3 displays the same information as a cumulative percentage. The information in Figures 2 and 3 is also presented in the

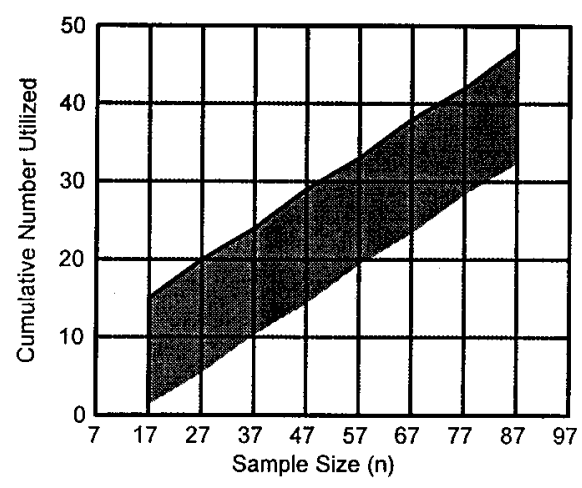

Fig. 2. Sequential sampling plan for $\pi_{o}=$ $0.40, \pi_{\mathrm{a}}=0.50, \alpha=0.05$, and $\beta=0.05$. Stop grazing if cumulative utilization is above the upper band, continue grazing if cumulative number of utilized plots is below the lower band, otherwise continue sampling.

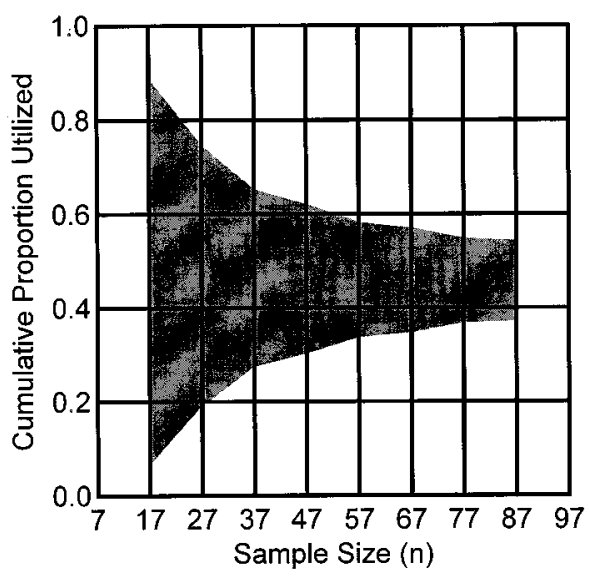

Fig. 3. Sequential sampling plan for $\pi_{o}=$ $0.40, \pi_{\mathrm{a}}=0.50, \alpha=0.05$, and $\beta=0.05$. Stop grazing if cumulative utilization is above the upper band, continue grazing if cumulative \% utilized plots is below the lower band, otherwise continue sampling.

figures and in the table portion of the spreadsheet in Figure 7. In practice, if more than 5 or 6 transects are needed, i.e., if the cumulative sample size exceeds 100 , arrangements should be made to stop grazing soon because the actual utilization is likely greater than the target value and fast approaching the alternative value.

\section{Practical Application}

- Max $n$

- Avg $n$

Fig. 1. Simulation results for 1,000 trials with $\pi_{o}=0.40, \pi_{\mathrm{a}}=0.50, \alpha=0.05$, and $\beta=0.05$.
Riparian pastures are typically heterogeneous in nature and often serpentine in form. Thus, sampling valley bottoms by random or systematic grid procedures is not very efficient, particularly when sam- 


\section{Spreadsheet to define sequential sampling rules}

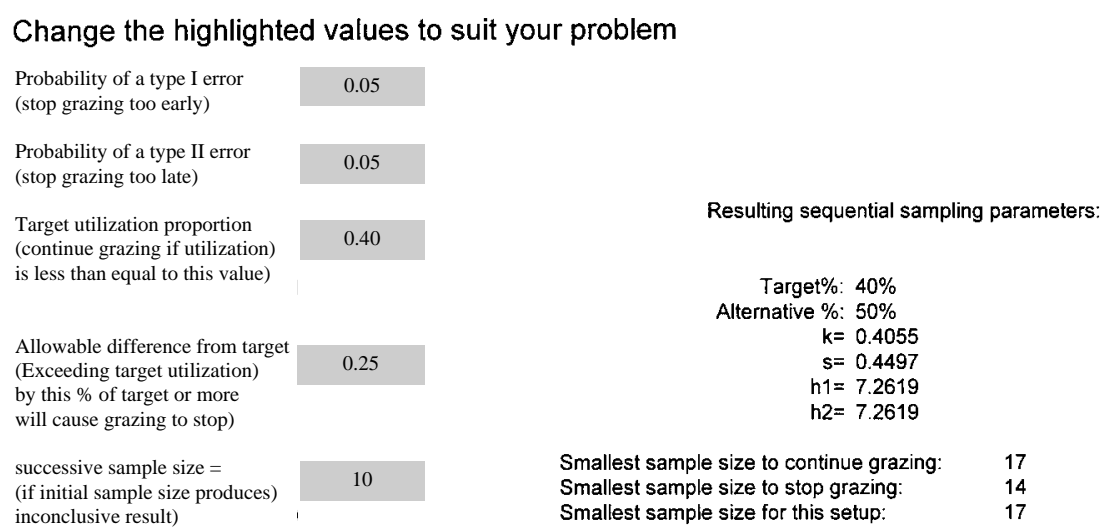

Table 1. Sampling Plan: Continue if cumulative count or percentage is less than or equal, stop if cumulative count or percentage is greater than or equal to table value

\begin{tabular}{|c|c|c|c|c|c|}
\hline $\begin{array}{c}\text { Pass } \\
\text { Number }\end{array}$ & $\begin{array}{c}\text { Cumulative } \\
\text { Sample } \\
\text { Size }\end{array}$ & $\begin{array}{c}\text { Cumulative } \\
\text { Continue } \\
\text { Count }\end{array}$ & $\begin{array}{c}\text { Cumulative } \\
\text { Stop } \\
\text { Count }\end{array}$ & $\begin{array}{c}\text { Cumulative } \\
\text { Continue } \\
\text { Proportion }\end{array}$ & $\begin{array}{c}\text { Cumulative } \\
\text { Stop } \\
\text { Proportion }\end{array}$ \\
\hline \hline 1 & 17 & 1 & 15 & 0.059 & 0.882 \\
2 & 27 & 5 & 20 & 0.185 & 0.741 \\
3 & 37 & 10 & 24 & 0.270 & 0.649 \\
4 & 47 & 14 & 29 & 0.298 & 0.617 \\
5 & 57 & 19 & 33 & 0.333 & 0.579 \\
6 & 67 & 23 & 38 & 0.343 & 0.567 \\
7 & 77 & 28 & 42 & 0.364 & 0.545 \\
8 & 87 & 32 & 47 & 0.368 & 0.540 \\
\hline
\end{tabular}

If a ninth pass is needed, arrangements should be made to stop grazing soon because the target and the alternative values are very close.

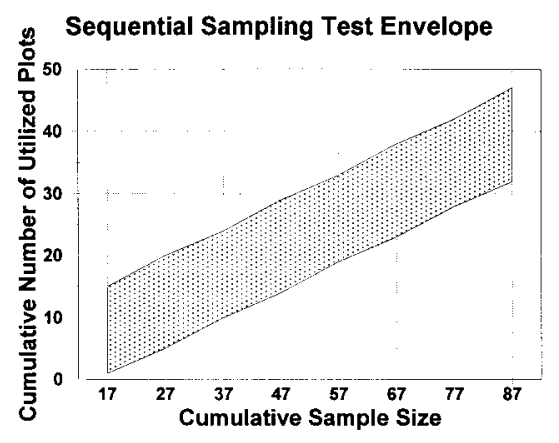

Sequential Sampling Test Envelope

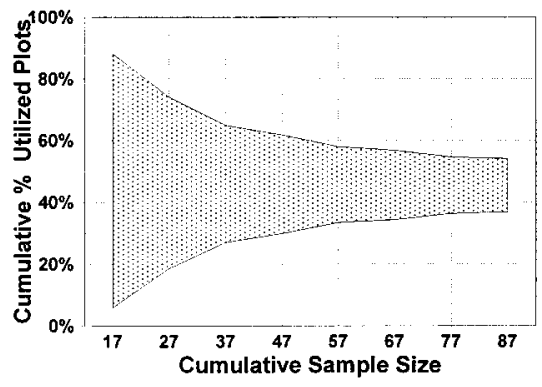

Fig. 4. Spreadsheet example for computing a sampling plan.

pling for characteristics applicable to specific strata such as streamside or drier portions. Under current management approaches, typical stubble height criteria might be a $5 \mathrm{~cm}$ height on the dry portion of a valley, and/or a $10 \mathrm{~cm}$ height on the wetmeadow or streamside portion of the same valley. Regardless of whether a single criterion or both are used, a typical riparian area would have to be stratified into at least two strata, a comparatively narrow and sinuous streamside or wet meadow strata and the remainder. A decision to stop grazing in either strata would stop grazing in the entire pasture unless grazing in the unstopped strata could continue while stopping in the other strata.

In some cases, the stream is straight enough and the wet-meadow area wide enough that a straight pace transect can be used to sample this strata. Often sampling is best conducted as a "wandering" transect changing direction as necessary to follow the approximate orientation of the long axis of the stratum. The general procedure would be to estimate the total length of the stratum one wishes to sample. A simple spreadsheet (Fig. 4) can be used to determine the minimum sample size and continue/stop criteria for specific $\pi_{o}, \pi_{\mathrm{a}}, \alpha$, and $\beta$ values. The sampler would use this minimum or larger number for the initial sample. For example, if the stratum is approximately 300 paces long and the minimum sample size is 20 , then a sample plot would be classified every 15 paces. If the first transect does not provide a definitive answer, additional transects are taken until a conclusion is reached or until the sample size exceeds approximately 100 points ( 5 or 6 transects). If no conclusion is reached after a sample size of that magnitude, it is generally safe to conclude that the true population utilization is close to a decision point and planning to stop-grazing in the near future is justified.

The transects or portions of transects would be sampled by picking a distant landmark and pacing without regard to the specific ground conditions to the next measurement point, in this example, every 15 paces. If necessary, the transect would change direction when the stratum changed direction to maintain the orientation with the long axis of the stratum. If additional transects are needed to arrive at a conclusion, they would also be oriented to the long axis of the stratum and, therefore, would approximately parallel the original transect.

We found that $1.25 \mathrm{~m}$ poles, cut from clothes hanger rods with a wrist loop attached and used as walking sticks, were useful in determining whether a plot was utilized. Using this pole with plastic tape bands to mark the height standards, one could read most plots by merely slowing one's pace (see Figs. 5 and 6). Additional useful equipment includes hand-held tally meters. These are used to keep track of total plots evaluated and the number of plots utilized. Using both the reference walking stick and the tally meters, a statistically meaningful survey can be rapidly completed and a scientifically defensible decision made. 


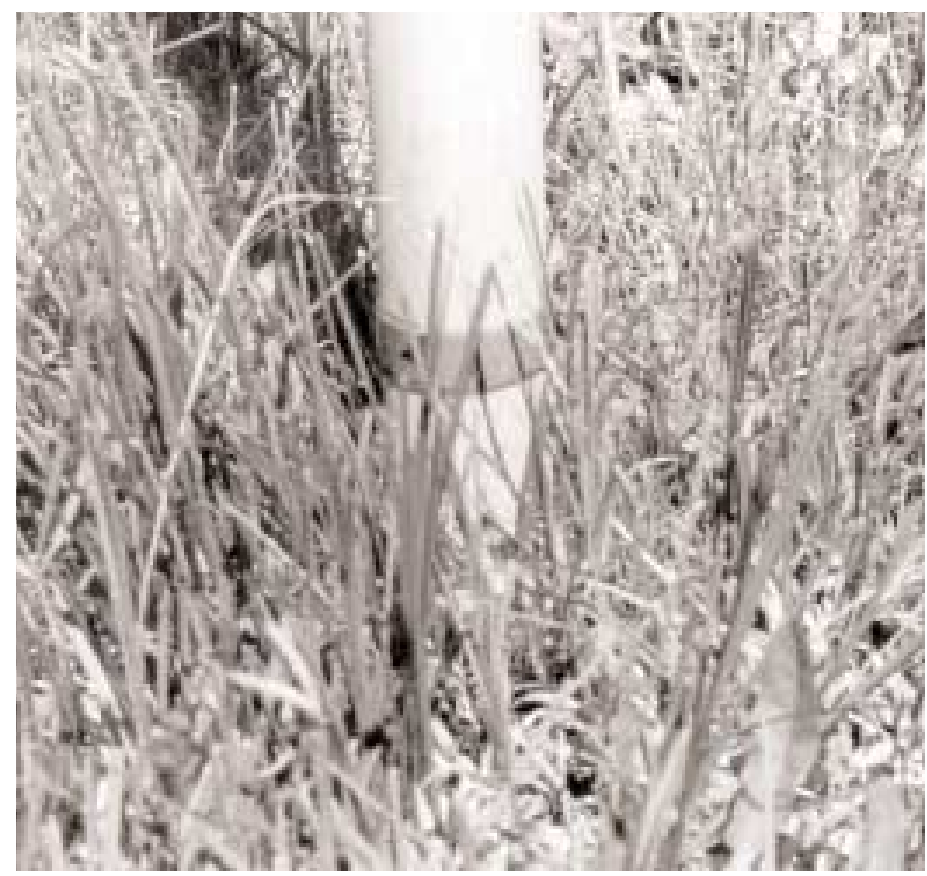

Fig. 5. Walking stick/tally pole with tape indicating utilization. This plot would be classified as not utilized.

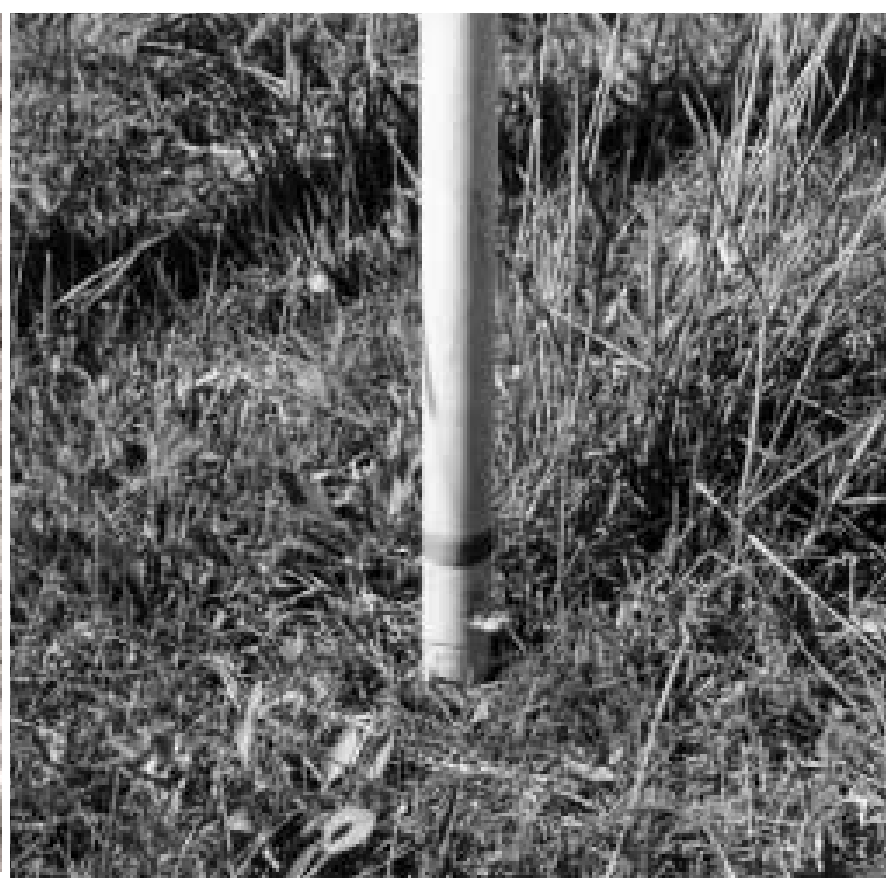

Fig. 6. Walking stick/tally pole with tape indicating utilization. This plot would be classified as utilized even though there is some vegetation above the tape mark.

\section{Field Trial}

\section{Methods and Materials}

Field trials were conducted using a pole with 2 bands of tape at 5 and $15 \mathrm{~cm}$ from the bottom. A pasture in the Stanley Basin of central Idaho (Lat $114^{\circ} \mathrm{W} 57^{\prime} 56^{\prime \prime}$, Long $\left.44^{\circ} \mathrm{N} 13^{\prime} 46^{\prime \prime}\right)$ was stratified into wet and dry areas, and samples were taken in both strata. A circle of radius $15 \mathrm{~cm}$ around a pole was used to assess the stubble height at each sampled location (plots need to be small enough so that it is visually obvious whether or not they were utilized). Plots were judged to be utilized if the average stubble height in a $15 \mathrm{~cm}$ radius circle around the pole was shorter than the $5 \mathrm{~cm}$ mark in the dry portion of the pasture or the $15 \mathrm{~cm}$ mark in the wet area. Figures 5 and 6 show pole placement for plots judged as nonutilized and utilized, respectively. As in the example described above, the probability of type I and II errors was set at $\alpha=0.05$ and $\beta=0.10$, respectively. The target and alternative proportions were set at .50 and .60 , respectively. Three observers tried the sequential procedure using an initial sample of 13 and successive samples (if needed) of 10.

\section{Results}

Figure 7 depicts the sampling stop/continue envelope along with the samples obtained by 3 observers. In the first transect in the dry area, observer 1 found 3 of the 13 or $23 \%$ of the samples were utilized. Since this is in the "no decision" or "continue sampling" area of Figure 7, at least 1 more transect must be sampled. The cumulative utilization after the second transect was 9 out of 23 or $39 \%$, still inside the "no decision" area. After the third transect, there were 11 of 33 or $33 \%$ utilized, still in the continue sampling region. After the fourth transect, the first

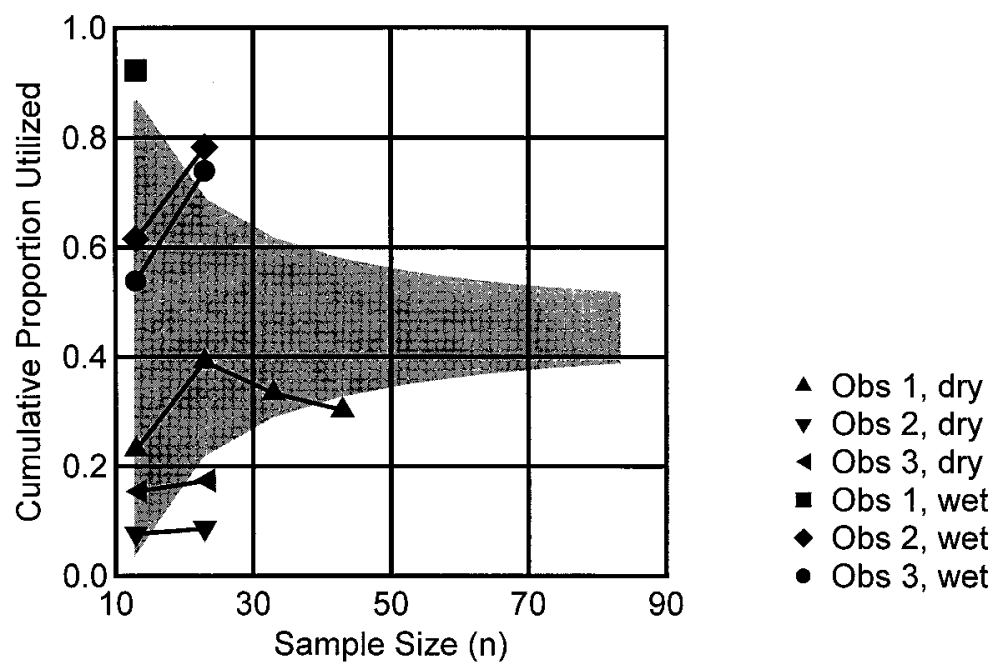

Fig. 7. Wet and dry sampling results for 3 observers. Type I and II errors ( $\alpha$ and $\beta$ ) were set to 0.10 , target and alternative utilization proportions $\left(\pi_{o}\right.$, and $\pi_{a}$, were .40 and .50 , respectively. All 3 observers decided to stop grazing in the wet area but allow continued grazing in the dry area based on different length criterion for each area. 
cumulative proportion well below the "continue" line in Figure 7 and, therefore, allowed grazing to continue. Observer 3 had a similar experience with $15 \%$ utilization (2 of 13) in the first transect and $17 \%$ (4 of 23) in the second which also allowed grazing to continue in the dry area.

In the wet area, all 3 observers concluded that grazing should stop. Observer 1 reached that conclusion on the first transect while observers 2 and 3 reached their conclusion on the second transect (Fig. 7). Since it was not possible or practical to fence off the wet area from the dry area at this location, the decision was to stop grazing.

For other scenarios, Figure 4 illustrates a spreadsheet developed to allow easy comparison of sampling plans. Five values must be specified to generate a specific sampling scheme: $\alpha$ and $\beta$ the probabilities of type I and II errors ( 0.05 is a common value); the target utilization proportion $\pi \mathrm{o},(0.40$ or 0.50 is usual); the allowable difference from the target as a percentage of the target value ( 0.20 or 0.25 of $\pi_{o}$, added on to the target value); and successive sample size (usually at least $10 \%$, but 20 or $25 \%$ is more realistic) making $\pi_{a}$ equal to $\pi_{o},(1+$ difference $)$. A copy of the spreadsheet in Excel format is available at http://www.fs.fed.us/rm/boise or may be requested by sending an e-mail to DLTurner@fs.fed.us.

\section{Conclusion}

Many resource managers have used ad hoc sampling methods to decide when a pasture has been utilized to a particular stubble height standard. This paper outlined a theoretically sound method of sequential sampling for making accurate and objective determinations of whether a grazed area had been utilized to a specified stubble height. Trampling impacts or other such "yes/no" measures may also be evaluated using this technique. With the ease of the sequential method, there is little excuse for not keeping a careful eye on pasture conditions.

\section{Literature Cited}

Canfield, R.H. 1942. A short-cut method for estimating grazing use. USDA Forest Serv. Southwest For. and Range Exp. Sta. Res. Note 99.

Clary, W.P. and W.C. Leininger.. Stubble height as a tool for management of riparian areas: a review. Submitted to J. of Range Manage. (In Press).

Hall, F.C. and L. Bryant. 1995. Herbaceous stubble height as a warning of impending cattle grazing damage to riparian areas. USDA For. Serv. Gen. Tech. Rep. PNWGTR-362.
Leonard, S., G. Kinch, V. Elsbernd, M. Borman, and S. Swanson. 1997. Riparian area management. USDI Bur. Land Manage. Tech. Ref. 1737-14.

Mood, A. M., F.A. Graybill, and D.C. Boes. 1974. Introduction to the Theory of Statistics. McGraw-Hill Book Co., New York, N.Y.

Moore, D.S. and G.P McCabe. 1989. Introduction to the Practice of Statistics. W.H. Freeman and Co., New York, N.Y.

Mosley, J.C., P.S. Cook, A.J. Griffis, and J. O'Laughlin. 1997. Guidelines for managing cattle grazing in riparian areas to protect water quality: review of research and best management practices policy. Idaho For. Wildl. and Range Exp. Sta.. Policy Analysis Group Rep. 15.

Oregon State University. 1998. Stubble height and utilization measurements: uses and misuses. Oreg. State Univ. Agr. Exp. Sta. Bull. 682.

Ostle, B. and R.W. Mensing. 1975. Statistics in Research, Third Edition. The Iowa State University Press, Ames, Iowa.

USDA Forest Service. 1993. Desk guide: bridge to revision. USDA For. Serv., Intermountain Region. Ogden, Ut.

USDA Forest Service. 1994. Rangeland analysis and management training guide. USDA For. Serv., Rocky Mountain Region. Denver, Colo.

USDA Natural Resource Conservation Service. 1999. Prescribed Grazing. In: Idaho Agricultural Pollution Abatement Plan. Division of Enviromental Quality and Idaho Soil Conservation Commission, Boise, Ida. 